\title{
Elevations of inflammatory proteins in neonatal blood are associated with obesity and overweight among 2-year-old children born extremely premature
}

\author{
Eliana M. Perrin ${ }^{1}$, T. Michael O'Shea ${ }^{2}$, Asheley Cockrell Skinner ${ }^{3}$, Carl Bose ${ }^{2}$, Elizabeth N. Allred ${ }^{4}$, Raina N. Fichorova ${ }^{5}$, \\ Jelske W. van der Burg ${ }^{6}$ and Alan Leviton ${ }^{4}$
}

BACKGROUND: Childhood obesity is associated with elevated blood concentrations of inflammation markers. It is not known to what extent inflammation precedes the development of obesity.

METHODS: In a cohort of 882 infants born before 28 weeks of gestation, we examined relationships between concentrations of 25 inflammation-related proteins in blood obtained during the first two postnatal weeks and body mass index at 2 years of age.

RESULTS: Among children delivered for spontaneous indications $(n=734)$, obesity was associated with elevated concentrations of four proteins (IL-1 $\beta, \mathrm{IL}-6, \mathrm{TNF}-\mathrm{R} 1$, and MCP-1) on the first postnatal day; one protein (IL-6) on postnatal day 7; and two proteins (ICAM-3 and VEGF-R1) on postnatal day 14. Among children delivered for maternal or fetal indications $(n=148)$, obesity was associated with elevated concentrations of seven proteins on the 14th postnatal day. In multivariable models in the spontaneous indications subsample, elevated IL-6 on day 1 predicted obesity (odds ratio: 2.9; 95\% confidence limits: 1.2, 6.8), whereas elevated VCAM-1 on day 14 predicted overweight at 2 years of age (odds ratio: 2.3; 95\% confidence limits: 1.2, 4.3).

CONCLUSIONS: In this cohort, neonatal systemic inflammation preceded the onset of obesity, suggesting that inflammation might contribute to the development of obesity.

$\mathbf{U}$ sing current expert panel definitions, which define obesity in children as a body mass index (BMI) at or above the 95th percentile for age and sex, and overweight as between the 85th and 95th percentiles, 33\% of US children and adolescents are overweight or obese (1). Childhood obesity is associated with increased risk of numerous health problems, particularly cardiometabolic disorders (2). Because of the morbidity and mortality related to obesity, identifying possible precursors is of utmost importance.

Several prenatal and early-infancy factors predict obesity in later childhood. Maternal pre-pregnancy obesity (3), high maternal gestational weight gain (4), and maternal gestational diabetes (5) are all antenatal risk factors for later obesity. Preterm birth is a perinatal risk factor (6), as is greater weight gain within the first postnatal week (7).

Obesity in adults is characterized by a state of chronic lowgrade inflammation (8). Children with obesity (9) and children with elevated measures of adiposity (10) are more likely than others to have high circulating levels of several markers of inflammation, including both proinflammatory cytokines and acute-phase proteins. Most investigators explain this relationship by hypothesizing that obesity promotes inflammation. An alternative (and/or additional) explanation is that some inflammation precedes the obesity (11). Prenatal and perinatal exposures might increase inflammatory mediators that play a role in metabolic programming (appetite control or hormonal environment) through epigenetic regulation of gene expression (12).

Scant research addresses temporality between inflammation and obesity in childhood, and no studies examine the relationship between elevated perinatal concentrations of circulating inflammatory proteins and subsequent obesity. Therefore, we sought to evaluate to what extent neonatal inflammation is an antecedent of early childhood obesity in a preterm population. In a cohort of infants born prior to 28 weeks of gestation (extremely low gestational age newborns; ELGANs), we investigated the relationship between circulating inflammation-related proteins measured during the first few postnatal weeks and obesity at the age of 2 years, when BMI standards are well defined. We studied children who were born extremely preterm because children born prematurely and those born small for gestational age (SGA) 


\section{Neonatal inflammation and obesity at age 2 Articles}

are at increased risk of obesity in childhood compared with children born at term, independent of other demographic, physiological, environmental, and cultural factors also related to obesity $(6,13)$.

\section{METHODS}

\section{Study Participants}

The ELGAN study was originally designed to identify characteristics and exposures that increase the risk of structural and functional neurologic disorders in ELGANs (14). During the years 2002-2004, 1,249 mothers of 1,506 infants delivered before 28 weeks of gestation at one of 14 participating institutions in the United States consented for their children's participation in the study. Data collection tools and procedures were uniform across the 14 sites. The enrollment and consent processes were approved by the individual institutional review boards. Twelve hundred participants survived to 2 years of age (age adjusted for degree of prematurity) and 1,056 of these children came for neurodevelopmental and health assessments at that age. From the subset of study participants who came for evaluation at 2 years, we had measurements of inflammation-related blood proteins measured in blood spots obtained during the first two postnatal weeks and measurement of height and weight at 2 years for 882 children $(73.5 \%$ of all survivors and $83.5 \%$ of survivors who were evaluated at 2 years).

\section{Demographic and Pregnancy Variables}

After delivery, a trained research nurse interviewed each mother in her native language using a structured data collection and following procedures contained in a manual. The mother's report of her own characteristics and exposures, as well as the sequence of events leading to preterm delivery was taken as truth, even when her medical record provided discrepant information. The maternal report disagreed with the clinical record in $<5 \%$ of comparisons, and in our experience has been more internally consistent than what physicians recorded in medical records (15).

Shortly after discharge, the research nurse reviewed the maternal chart using a second structured data collection form to collect information about events after admission. The spontaneous initiators of preterm delivery (i.e., preterm labor, prelabor rupture of the fetal membranes, placental abruption, and cervical insufficiency), maternal indicators (including preeclampsia), and delivery for fetal indications are defined elsewhere (15).

\section{Pre-Pregnancy Maternal BMI}

Each mother was asked to provide her height and her pre-pregnancy weight, which were used to calculate her BMI. The US government classifies adult BMIs as follows: $<18.5$ is underweight, 18.5-24.9 is healthy weight, $25.0-29.9$ is overweight, $30.0-34.9$ is obese, $35.0-39.9$ is very obese, and $\geqslant 40$ is extreme obesity (16). We collapsed the five groups down to three: $<18.5,18.5-29.9$, and $\geqslant 30$.

\section{Placentas}

A placenta was examined histologically for all but 72 of the infants. In keeping with the guidelines of the 1991 College of American Pathologists Conference, representative sections were taken from all abnormal areas, as well as routine sections of the umbilical cord and a membrane roll, and full-thickness sections from the center and a paracentral zone of the placental disk. After training to minimize observer variability, study pathologists examined the slides for histologic characteristics listed on a standardized data form that they helped to create (17). Histologic chorioamnionitis was classified as grade 3 if the membranes and/or decidua had numerous large or confluent foci of neutrophils and as grade 4 if necrosis was present.

\section{Infant Characteristics}

Gestational age estimates were based on a hierarchy of the quality of available information with estimates based on the dates of embryo retrieval or intrauterine insemination or fetal ultrasound before the 14th week of gestation (62\%) as the most desirable. The next most desirable in sequential order were estimates based on a fetal ultrasound at 14 or more weeks of gestation (29\%), last menstrual period $(7 \%)$, and recorded in the log of the NICU.

The birth weight $\mathrm{Z}$ score represents the number of standard deviations of the infant's birth weight was above or below the mean weight of infants at the same gestational age in reference samples not delivered for maternal or fetal indications (18).

The overall change in weight over the interval between day 7 and day 28 was expressed as the difference between the weight on day 7 and the weight on day 28 , divided by the weight on day 7 , in kilograms. The growth velocity per day was then calculated by dividing the overall weight change per kilogram of body weight by 21 , the number of days in the interval between day 7 and day 28 .

Documented early bacteremia was defined as recovery of an organism from blood drawn during the first week, and late bacteremia as recovery of an organism from blood drawn during weeks 2, 3, or 4. Specific organisms were not identified.

The child's necrotizing enterocolitis status was classified according to the modified Bell staging system (19). Chronic lung disease/ bronchopulmonary dysplasia was defined as oxygen therapy at 36 weeks of adjusted gestation.

\section{BMI at 2 Years}

Height and weight, measured during the examination component of ELGAN, were used to calculate BMI (weight in kilograms divided by height in meters squared). Each child's BMI percentile for sex and age was determined by comparison to the CDC growth chart percentiles. Children with weight $\geqslant 95$ th percentile are considered obese; those with weight $\geqslant 85$ th to $<95$ th percentile are considered overweight; and those with weight to $\geqslant 5$ th to $<85$ th percentile are of healthy weight (20).

\section{Blood Spot Collection}

Drops of blood from the newborns were collected on filter paper on postnatal days 1 (range: $1-3$ days) $(N=861), 7$ (range: $5-8$ days) $(N N=867)$, and 14 (range: $12-15$ days) $(N=786)$. All blood was from what remained after specimens were obtained for clinical indications. Dried blood spots were stored at $-70{ }^{\circ} \mathrm{C}$ in sealed bags with desiccant until processed.

\section{Protein Measurements}

Additional details about the elution of proteins from the blood spots and measurement of proteins have been previously reported (21) (Supplementary Table S1 online). Proteins were measured in duplicate in the Laboratory of Genital Tract Biology of the Department of Obstetrics, Gynecology, and Reproductive Biology at Brigham and Women's Hospital, Boston using the Meso Scale Discovery (MSD) multiplex platform and Sector Imager 2400 (MSD, Gaithersburg, MD). This electrochemiluminescence system has been validated by comparisons with traditional ELISA and produces measurements that have high content validity (21).

The multiplex assays measuring up to 10 proteins simultaneously were optimized to allow detection of each biomarker within the linearity range of the eluted samples. The MSD Discovery Workbench Software was used to convert relative luminescent units into protein concentrations using interpolation from several log calibrator curves. Split quality control blood pools tested on each plate showed inter-assay variation of $<20 \%$ in the linearity range customized for the blood spot elution samples. The total protein concentration in each eluted sample was determined by BCA assay (Thermo Scientific, Rockford, IL) using a multi-label Victor 2 counter (Perkin Elmer, Boston, MA) and the measurements of each inflammation protein normalized to $\mathrm{mg}$ of total protein. 


\section{Articles $\mid$ Perrin et al.}

We measured the following 25 proteins: C-reactive protein (CRP), serum amyloid A (SAA), myeloperoxidase (MPO), interleukin-1 beta IL-1 beta, interleukin-6 (IL-6), interleukin-6 receptor (IL-6R), tumor necrosis factor-alpha (TNF-alpha), tumor necrosis factor-alpha receptor-1 (TNF-R1), tumor necrosis factor-alpha receptor-2 (TNF-R2), interleukin-8 (IL-8; CXCL8), monocyte chemotactic protein-1 (MCP-1; CCL2), monocyte chemoattractant protein-4 (MCP-4; CCL13), macrophage inflammatory protein-1 beta (MIP-1 beta; CCL4), regulated upon activation, normal T-cell expressed, and [presumably] secreted (RANTES; CCL5), interferon-inducible T cell alpha-chemoattractant (I-TAC; CXCL11), intercellular adhesion molecule-1 (ICAM-1; CD54), intercellular adhesion molecule-3 (ICAM-3; CD50), vascular cell adhesion molecule-1 (VCAM-1; CD106), E-selectin (CD62E), matrix metalloproteinase-1 (MMP-1), matrix metalloproteinase-9 (MMP-9), vascular endothelial growth factor (VEGF), vascular endothelial growth factor receptor-1(VEGFR1; Flt-1), vascular endothelial growth factor receptor-2 (VEGF-R2; KDR), and insulin growth factor binding protein-1 (IGFBP-1).

\section{Data Analysis}

We evaluated the null hypothesis that ELGANS who have concentrations of inflammation-related proteins in the top quartile during the first two postnatal weeks are no more likely than others to be overweight or obese at 24 months.

We evaluated children delivered for spontaneous indications separately from those delivered for fetal or maternal indications for two reasons. First, in this sample, concentrations of inflammationassociated proteins in postnatal blood differ between these two groups (22). Second, in this sample, the prevalence of fetal growth restriction was much higher among infants delivered for maternal or fetal indications than among those delivered for spontaneous indications (23).

We first explored to what extent perinatal variables are related to growth velocity and to 2-year BMI category in groups of infants delivered for spontaneous indications and for maternal and fetal indications. We then explored the distribution of inflammationrelated protein concentrations in the top quartile among 2-year BMI categories during each of three time intervals during the first few postnatal weeks, separately for children whose birth was prompted by spontaneous indications and maternal/fetal indications.

We used time-oriented multivariable regression, specifically multinominal logistic regression, to control confounding (24). This time-oriented approach to model selection is appropriate because antenatal antecedents of BMI at 2 years can influence the likelihood of postnatal antecedents. We categorized sets of antecedents by the time they occur, or are identified (e.g., antenatal, days 1, 7, and 14 protein measures, and later postnatal). We then used a step-down procedure, seeking a parsimonious solution without interaction terms. The initial step in this multistep analysis included only prenatal variables. We eliminated variables that were not significantly associated with overweight and obesity until the only variables that remained were those significantly associated with either overweight or obesity. We then reentered each previously eliminated variable to see if it might add significant information to the most parsimonious model. Only those variables with statistically significant associations with BMI at 2 years were carried forward to the next step. The second, third, and fourth steps considered days 1, 7, and 14 protein variables, respectively. At each step, nonsignificant variables were dropped and statistically significant variables retained from earlier steps could not be dropped. Dropped variables were reconsidered as described for step 1. Having "adjusted" for prenatal variables and proteins on days 1,7 , and 14 , we added variables for the lowest and highest quartiles of growth velocity between days 7 and 28 to see if they added significant information about child overweight and obesity at 2 years. These models allowed us to calculate odds ratios and $95 \%$ confidence intervals. The multinomial outcome was BMI centile 85-94 (overweight) and $\geqslant 95$ (obese) and BMI centile $<85$ (healthy weight) was the reference category.

\section{RESULTS}

\section{Sample Description}

Children who were members of the cohort but were not evaluated at 2 years were more likely to have been born to mothers with pregnancy weight gain in the lowest quartile for our sample and were more likely to have had gestational diabetes (Table 1). Of the 882 infants in the study sample, 734 were delivered for spontaneous indications, and 148 were delivered for maternal $(N=114)$ or fetal indications $(N=34)$. Among infants who survived to 28 days and were weighed on both occasions, the upper bound of the lowest quartile of growth velocity was 13.8 , the median was 18.3 , and the upper bound of the third quartile was 22.6 .

\section{Infants Delivered for Spontaneous Indications}

Infants with obesity at the age of 2 years were more likely than others to have a mother who was identified as Black, and who was obese prior to her pregnancy (Table 2). The proportion of children whose placenta was inflamed increased with increasing 2-year BMI. Children with obesity were less likely than others to be male, have a twin or triplet, or a birth weight at or below $750 \mathrm{~g}$, and more likely to have had an early growth velocity in the top quartile.

\section{Infants Delivered for Maternal or Fetal Indications}

Infants who had necrotizing enterocolitis or chronic lung disease were more likely than others to be obese at the age of 2 years (Table 3). They were less likely than others to have a mother with obesity just before pregnancy, to be male, or to have been born during the 23rd or 24th week of gestation.

\section{Protein Concentrations in the Blood of Infants Delivered for Spontaneous Indications}

Among children who are obese, the frequency of a top-quartile day- 1 concentration of IL- $1 \beta$, IL-6, TNF-R1, and MCP- 1 was 1.5-1.9 times greater than the frequency among healthy weight children (Table 4). Children who were obese had a frequency of top-quartile day-7 concentration of IL- 6 and top-quartile concentrations of ICAM-3 and VEGF-R1 on day 14 that were at least 1.5 times that of healthy weight children. Children who were overweight had frequencies of a top-quartile day-1 concentration of VCAM-1, a top-quartile day-7 concentration of IL-1 $\beta$, and a top-quartile day-14 concentration of IL-6R, ICAM-1, and VCAM-1 that was at least 1.5 times that of healthy weight children. Overweight children were 3 times less likely to have a top-quartile day-14 concentration of MMP-1.

\section{Protein Concentrations of Infants Delivered for Maternal or Fetal Indications}

With only a maximum of eight overweight children and 12 obese children, just one more or less child in either of these weight categories in the top quartile appreciably alters our perception of the proportion who have a concentration in the top quartile (Table 5). Children who were obese at 2 years were less likely than others to have had elevated concentrations of inflammation-related proteins in the day- 1 blood spot. This 
Table 1. The percent of children who are in or not in the analysis sample who also had the characteristic listed on the left

\begin{tabular}{|c|c|c|c|c|}
\hline \multirow[t]{2}{*}{$\begin{array}{l}\text { Characteristics of the } \\
\text { mother and infant }\end{array}$} & & \multicolumn{2}{|c|}{$\begin{array}{l}\text { In the analysis } \\
\text { sample? }\end{array}$} & \multirow[t]{2}{*}{ Row $\mathrm{N}$} \\
\hline & & Yes & No & \\
\hline Public insurance & Yes & 38 & 40 & 418 \\
\hline Black race & Yes & 28 & 22 & 291 \\
\hline Hispanic & Yes & 11 & 16 & 129 \\
\hline Pre-pregnancy & $<18.5$ & 8 & 7 & 82 \\
\hline BMI & $>30$ & 21 & 20 & 221 \\
\hline \multirow{2}{*}{$\begin{array}{l}\text { Pregnancy weight gain } \\
\text { quartile }\end{array}$} & Highest & 24 & 29 & 264 \\
\hline & Lowest & 24 & 47 & 238 \\
\hline Gestational diabetes & Yes & 49 & 67 & 37 \\
\hline \multirow[t]{2}{*}{ Histologic chorioamnionitis $^{\mathrm{a}}$} & Yes & 33 & 35 & 369 \\
\hline & Missing & 9 & 6 & 93 \\
\hline \multirow[t]{6}{*}{ Indication for delivery } & PTL & 45 & 46 & 498 \\
\hline & pPROM & 22 & 21 & 240 \\
\hline & PE & 13 & 14 & 144 \\
\hline & Abruption & 11 & 8 & 118 \\
\hline & Cerv insuf & 5 & 6 & 58 \\
\hline & $\mathrm{FI}$ & 4 & 5 & 44 \\
\hline Cesarean delivery & Yes & 66 & 69 & 736 \\
\hline Sex & Male & 52 & 50 & 569 \\
\hline No. of fetuses & $2+$ & 33 & 38 & 373 \\
\hline \multirow[t]{2}{*}{ Gestational age (weeks) } & $23-24$ & 21 & 16 & 220 \\
\hline & $25-26$ & 47 & 43 & 508 \\
\hline \multirow[t]{2}{*}{ Birth weight (g) } & $\leq 750$ & 37 & 31 & 397 \\
\hline & $750-1,000$ & 44 & 44 & 487 \\
\hline \multirow[t]{2}{*}{ BW Z score ${ }^{b}$} & $<-2$ & 5 & 5 & 58 \\
\hline & $\geqslant-2,<-1$ & 13 & 15 & 145 \\
\hline$\%$ Weight gain, week 1 & Highest Q & 24 & 23 & 257 \\
\hline \multirow[t]{2}{*}{ Growth velocity ${ }^{c}$ quartile } & Lowest & 24 & 29 & 266 \\
\hline & Highest & 24 & 18 & 249 \\
\hline \multirow[t]{2}{*}{ Bacteria in blood } & Week 1 & 6 & 7 & 69 \\
\hline & Week 2+ & 26 & 21 & 276 \\
\hline Necrotizing enterocolitis ${ }^{d}$ & Yes & 8 & 6 & 83 \\
\hline Chronic lung disease $\mathrm{e}^{\mathrm{e}}$ & Yes & 53 & 41 & 443 \\
\hline Maximum number of infants & & 882 & 220 & 1102 \\
\hline \multicolumn{5}{|c|}{$\begin{array}{l}\text { These are column percents. } \\
\text { a Grades } 3 \text { and } 4 . \\
\text { bYudkin standard. } \\
{ }^{\mathrm{c}} 1,000 \times[(\text { weight day } 28-\text { weight day } 7) / \text { weight day } 7] / 21 \text {. } \\
{ }^{\mathrm{d} S t a g e} \text { Illa, Illb, or perforation. } \\
\text { e Receiving oxygen at } 36 \text { weeks postconceptional age. }\end{array}$} \\
\hline
\end{tabular}

trend was less evident in the day-7 blood spot. Children who are obese were more likely than others to have had a day-14 topquartile concentration of CRP, MPO, IL-1 $\beta$, IL-6, TNF- $\alpha$, IL- 8 , MMP-9, and VEGF-R1. Overweight children were more likely than others to have a day-7 top-quartile concentration of SAA, IL-1 $\beta$, I-TAC, and IGFBP-1, and a day-14 top-quartile concentration of CRP, I-TAC, E-SEL, VEGF, and VEGF-R1.
Table 2. The percent of children who were in the BMI category listed at the top of the column who also had the characteristic listed on the left

\begin{tabular}{|c|c|c|c|c|c|}
\hline \multirow[t]{2}{*}{$\begin{array}{l}\text { Characteristics of the } \\
\text { mother and infant }\end{array}$} & & \multicolumn{3}{|c|}{$\begin{array}{l}\text { Child's BMI centile } \\
\text { at } 24 \text { months } \\
\end{array}$} & \multirow{2}{*}{ Row N } \\
\hline & & $<85$ & $85-94$ & $\geqslant 95$ & \\
\hline Public insurance & Yes & 40 & 29 & 39 & 281 \\
\hline Black race & Yes & 28 & 22 & 39 & 201 \\
\hline Hispanic & Yes & 11 & 10 & 6 & 80 \\
\hline \multirow[t]{2}{*}{ Pre-pregnancy BMI } & $<18.5$ & 9 & 9 & 0 & 62 \\
\hline & $>30$ & 18 & 19 & 35 & 134 \\
\hline \multirow{2}{*}{$\begin{array}{l}\text { Pregnancy weight gain } \\
\text { quartile }\end{array}$} & Highest & 23 & 19 & 16 & 158 \\
\hline & Lowest & 23 & 28 & 42 & 171 \\
\hline Gestational diabetes & Yes & 6 & 2 & 6 & 39 \\
\hline \multirow[t]{2}{*}{ Histologic chorioamnionitis ${ }^{a}$} & Yes & 39 & 43 & 47 & 289 \\
\hline & Missing & 10 & 7 & 9 & 72 \\
\hline \multirow[t]{4}{*}{ Indication for delivery } & PTL & 55 & 45 & 50 & 396 \\
\hline & pPROM & 27 & 27 & 21 & 193 \\
\hline & Abruption & 13 & 20 & 18 & 101 \\
\hline & Cerv insuf & 5 & 8 & 12 & 44 \\
\hline Cesarean delivery & Yes & 62 & 50 & 56 & 443 \\
\hline Sex & Male & 55 & 67 & 38 & 407 \\
\hline No. of fetuses & $2+$ & 38 & 30 & 12 & 265 \\
\hline \multirow[t]{2}{*}{ Gestational age (weeks) } & $23-24$ & 24 & 23 & 18 & 174 \\
\hline & $25-26$ & 46 & 47 & 47 & 339 \\
\hline \multirow[t]{2}{*}{ Birth weight (g) } & $\leq 750$ & 33 & 30 & 15 & 236 \\
\hline & $750-1,000$ & 48 & 45 & 50 & 348 \\
\hline \multirow[t]{2}{*}{ BW Z score ${ }^{\mathrm{b}}$} & $<-2$ & 2 & 2 & 0 & 14 \\
\hline & $\geqslant-2,<-1$ & 8 & 3 & 6 & 58 \\
\hline \% Weight gain, week 1 & Highest Q & 20 & 17 & 9 & 138 \\
\hline \multirow[t]{2}{*}{ Growth velocity ${ }^{c}$ quartile } & Lowest & 26 & 18 & 12 & 182 \\
\hline & Highest & 22 & 32 & 35 & 171 \\
\hline \multirow[t]{2}{*}{ Bacteria in blood } & Week 1 & 6 & 7 & 0 & 44 \\
\hline & Week 2+ & 25 & 30 & 24 & 188 \\
\hline Necrotizing enterocolitis ${ }^{d}$ & Yes & 8 & 5 & 9 & 58 \\
\hline Chronic lung disease $\mathrm{e}^{\mathrm{e}}$ & Yes & 50 & 62 & 47 & 373 \\
\hline Maximum number of infants & 640 & 60 & 34 & 734 & \\
\hline
\end{tabular}

These are column percents. This table is restricted to infants whose delivery was for spontaneous indications (including preterm labor, preterm premature rupture of membranes, abruption, or cervical insufficiency).

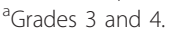

byudkin standard.

${ }^{c} 1,000 \times[($ weight day 28 - weight day 7$) /$ weight day 7$] / 21$.

${ }^{\mathrm{d}}$ Stage IIla, Illb, or perforation.

e Receiving oxygen at 36 weeks postconceptional age.

Multinomial, Time-Oriented Risk Models of the Antecedents of Being Overweight or Obese at Age 2 Years Among Infants Delivered for Spontaneous Indications

We addressed the contribution of antecedents to overweight (BMI centiles 85-94) and obesity (BMI centiles ₹95) that occurred before measurement of the day-1 proteins, by beginning 


\section{Articles | Perrin et al.}

Table 3. The percent of children who were in the BMI category listed at the top of the column who also had the characteristic listed on the left

\begin{tabular}{|c|c|c|c|c|c|}
\hline \multirow[t]{2}{*}{ Characteristics of the mother and infant } & & \multicolumn{3}{|c|}{ Child's BMI at 24 months } & \multirow[t]{2}{*}{ Row N } \\
\hline & & $<85$ & $85-94$ & $\geqslant 95$ & \\
\hline Public insurance & Yes & 35 & 38 & 42 & 52 \\
\hline Black race & Yes & 28 & 38 & 33 & 42 \\
\hline Hispanic & Yes & 9 & 25 & 0 & 13 \\
\hline Pre-pregnancy & $<18.5$ & 3 & 0 & 8 & 5 \\
\hline BMI & $>30$ & 33 & 50 & 8 & 46 \\
\hline Gestational diabetes & Yes & 10 & 13 & 17 & 16 \\
\hline \multirow[t]{2}{*}{ Histologic chorioamnionitis ${ }^{a}$} & Yes & 3 & 0 & 0 & 4 \\
\hline & Missing & 5 & 0 & 8 & 8 \\
\hline \multirow[t]{2}{*}{ Indication for delivery } & Preeclampsia & 77 & 88 & 75 & 114 \\
\hline & Fetal indications & 23 & 13 & 25 & 35 \\
\hline Cesarean delivery & Yes & 95 & 100 & 92 & 141 \\
\hline Sex & Male & 34 & 63 & 25 & 52 \\
\hline \# of fetuses & $2+$ & 15 & 25 & 33 & 25 \\
\hline \multirow[t]{2}{*}{ Gestational age (weeks) } & $23-24$ & 8 & 13 & 0 & 11 \\
\hline & $25-26$ & 47 & 63 & 75 & 74 \\
\hline \multirow[t]{2}{*}{ Birth weight (grams) } & $\leq 750$ & 60 & 88 & 67 & 92 \\
\hline & $750-1,000$ & 30 & 13 & 25 & 42 \\
\hline \multirow[t]{2}{*}{ BW Z score ${ }^{a_{, * * *}}$} & $<-2$ & 23 & 25 & 25 & 34 \\
\hline & $\geqslant-2,<-1$ & 35 & 63 & 33 & 55 \\
\hline \multirow[t]{2}{*}{ Growth velocity $^{\mathrm{b}}$ quartile } & Lowest & 20 & 12 & 17 & 28 \\
\hline & Highest & 27 & 38 & 42 & 43 \\
\hline \multirow[t]{2}{*}{ Bacteria in blood } & Week1 & 7 & 0 & 0 & 9 \\
\hline & Week2+ & 29 & 0 & 42 & 42 \\
\hline Necrotizing enterocolitis ${ }^{\mathrm{b}, \mathrm{t}}$ & Yes & 6 & 13 & 25 & 12 \\
\hline Chronic lung disease ${ }^{c}$ & Yes & 61 & 63 & 75 & 91 \\
\hline Maximum number of infants & & 128 & 8 & 12 & 148 \\
\hline $\begin{array}{l}\text { ** Yudkin standard. } \\
{ }^{++} \text {Stage IIla, Illb, or perforation } \\
\text { These are column percents. This table is restricte } \\
\text { a Grades } 3 \text { and } 4 \text {. } \\
{ }^{b} 1,000 \times[(\text { weight day } 28-\text { weight day } 7) / \text { weight } \\
{ }^{\mathrm{c}} \text { Receiving } \mathrm{O}_{2} \text { at } 36 \text { weeks PCA. }\end{array}$ & ho delivered for ma & ndicatic & & & \\
\hline
\end{tabular}

with a model that included characteristics evident at the time of delivery (Table 6). In its most parsimonious form, the risk of obesity was significantly reduced among boys (odds ratio $(\mathrm{OR})=0.4(95 \%$ confidence interval $(\mathrm{CI}): 0.2,0.99))$, children born with a sibling $(\mathrm{OR}=0.2(95 \% \mathrm{CI}: 0.1,0.7))$, or those whose birth weight was $\leq 750 \mathrm{~g}(\mathrm{OR}=0.2$ (95\% CI: 0.1, 0.8)).

When the top-quartile day- 1 protein concentrations were added to multivariable analysis of factors associated with overweight and obesity, only IL-6 added significant discriminating information about increased risk of obesity $(\mathrm{OR}=2.9$ (95\% CI: 1.2, 6.8)). No day-7 protein concentrations contributed to the model.

Adding top-quartile day-14 protein concentrations did not add significant information about obesity, but a top-quartile VCAM-1 concentration was associated with increased risk of being overweight $(\mathrm{OR}=2.3$ (95\% CI: $1.2,4.3)$ ), whereas a top-quartile MMP-1 concentration was associated with reduced risk $(\mathrm{OR}=0.2(95 \% \mathrm{CI}: 0.1,0.6))$.

Because growth velocity was measured for the 2nd through 4th weeks, variables for the highest and lowest quartiles of growth velocity were added after day-14 protein measurements. Neither the highest nor the lowest growth velocity quartile added significant information about the risk of being overweight or obese 2 years later, although the highest growth velocity quartile was nearly significantly associated with obesity at 2 years $(\mathrm{OR}=2.6$ (95\% CI: $1.00,6.5)$ ).

The relatively small sample of infants delivered for fetal or maternal indications did not allow for confidence in creating stable multivariable models. Consequently, no multivariable model of overweight or obesity at the age of 2 years is presented for the subsample of children delivered for fetal or maternal indications. 


\section{Neonatal inflammation and obesity at age 2}

Table 4. Percent of all children who had BMI at the top of each column at age 24 months who also had a concentration in the top quartile of the protein on the left on postnatal days 1,7 , and 14

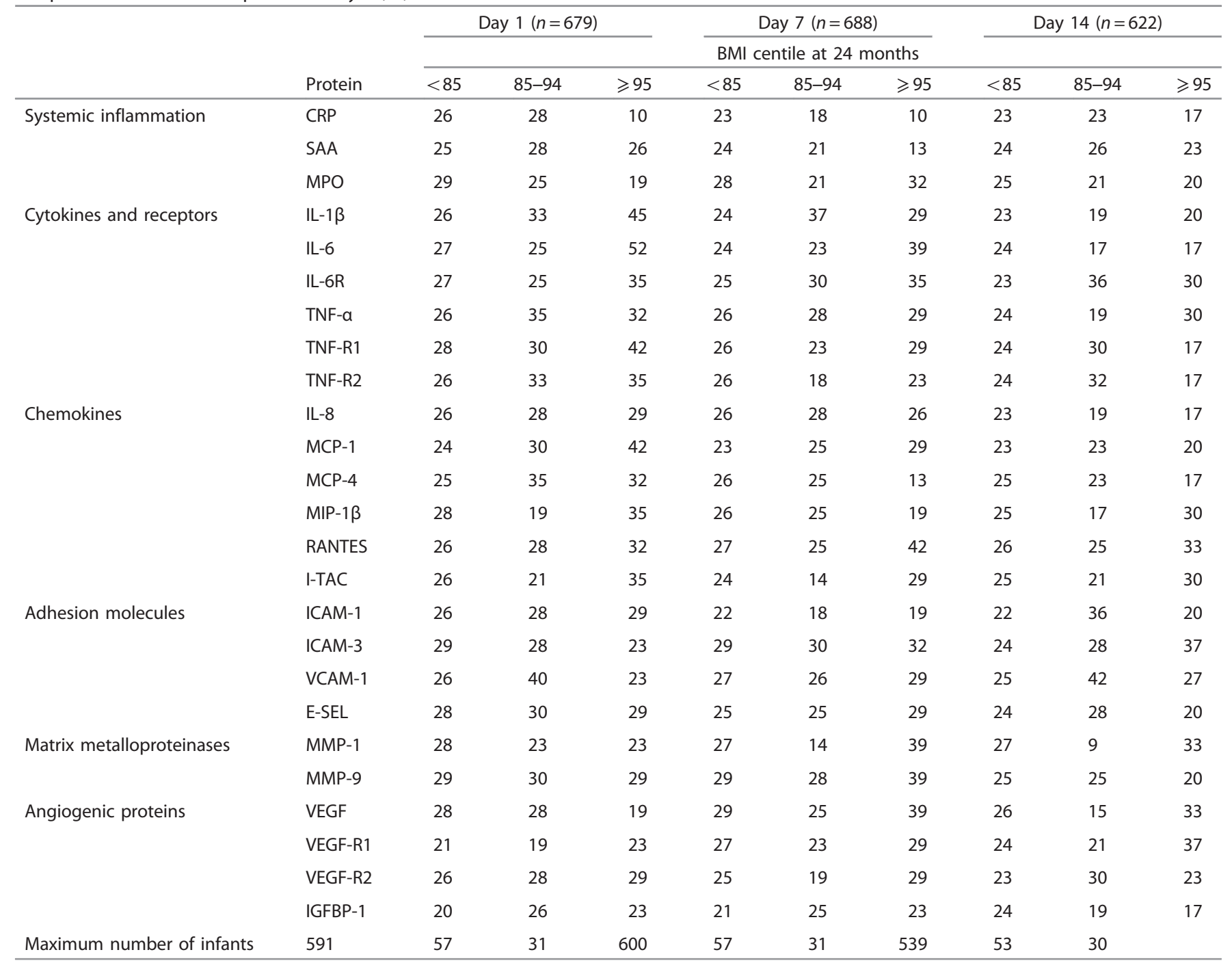

These are column percents. This table is restricted to infants who delivered for spontaneous indications (i.e., preterm labor, preterm premature rupture of membranes, abruption, or cervical insufficiency).

\section{DISCUSSION}

We have two major findings. First, among ELGANs who were delivered for spontaneous indications, infants who were obese at the age of 2 years were more likely than others to have had elevated levels of inflammation proteins in blood obtained on the first postnatal day. Second, among those who were delivered for maternal or fetal indications, the perinatal inflammation associated with obesity at the age of 2 years was first evident in blood obtained on postnatal day 14. Even after controlling for multiple other factors in parsimonious multivariable models of obesity risk in the larger spontaneous indications subsample, an elevated concentration of day-1 IL- 6 is a strong predictor of obesity at the age of 2 years, and an elevated concentration of day-14 VCAM-1 is a strong predictor of overweight. Thus, our findings support the hypothesis that inflammation can precede the onset of obesity, although obesity might well also exacerbate responses to inflammatory stimuli at later ages.

\section{Why Did the Pattern for Spontaneous Indications Differ from} the Pattern for Maternal/Fetal Indications?

The systemic inflammation evident on postnatal day 1 in those delivered for spontaneous indications might reflect in utero phenomena resulting in fetal, and hence, very early neonatal inflammation (25). In contrast, the systemic inflammation in those delivered for maternal or fetal indications probably reflects a relative absence of in utero inflammatory stimuli, and a proclivity to respond intensely to ex utero inflammatory stimuli $(22,26,27)$. The pattern of inflammatory cytokines related to obesity on day 14 among children who were delivered for maternal or fetal indications was similar to the day-1 pattern for children delivered for spontaneous indications. 


\section{Articles | Perrin et al.}

Table 5. Percent of all children who had the BMI at the top of each column at the age of 2 years who also had a concentration in the top quartile of the protein on the left on postnatal days 1,7 , and 14

\begin{tabular}{|c|c|c|c|c|c|c|c|c|c|c|}
\hline & \multirow[b]{3}{*}{ Protein } & \multicolumn{3}{|c|}{ Day $1(n=134)$} & \multirow{2}{*}{\multicolumn{3}{|c|}{$\begin{array}{c}\text { Day } 7(n=136) \\
\text { BMI centile at } 24 \text { months }\end{array}$}} & \multicolumn{3}{|c|}{ Day $14(n=128)$} \\
\hline & & \multirow[b]{2}{*}{$<85$} & \multirow[b]{2}{*}{$85-94$} & \multirow[b]{2}{*}{$\geqslant 95$} & & & & \multirow[b]{2}{*}{$<85$} & \multirow[b]{2}{*}{$85-94$} & \multirow[b]{2}{*}{$\geqslant 95$} \\
\hline & & & & & $\begin{array}{c}<85 \\
47\end{array}$ & $\frac{85-94}{14}$ & $\begin{array}{r}\geqslant 95 \\
33\end{array}$ & & & \\
\hline \multirow{2}{*}{ Systemic inflammation } & SAA & 24 & 0 & 8 & 38 & 43 & 17 & 32 & 25 & 22 \\
\hline & MPO & 10 & 13 & 8 & 14 & 14 & 17 & 27 & 13 & 56 \\
\hline \multirow{4}{*}{ Cytokines and receptors } & IL-6R & 18 & 25 & 0 & 22 & 0 & 33 & 30 & 0 & 33 \\
\hline & TNF-a & 16 & 13 & 0 & 26 & 29 & 29 & 36 & 25 & 67 \\
\hline & TNF-R1 & 13 & 0 & 0 & 29 & 14 & 17 & 31 & 38 & 33 \\
\hline & TNF-R2 & 15 & 13 & 0 & 33 & 14 & 17 & 32 & 13 & 22 \\
\hline \multirow{3}{*}{ Chemokines } & MIP-1 $\beta$ & 16 & 25 & 8 & 26 & 14 & 8 & 31 & 38 & 22 \\
\hline & RANTES & 18 & 13 & 0 & 15 & 0 & 8 & 25 & 38 & 0 \\
\hline & I-TAC & 19 & 25 & 8 & 28 & 43 & 17 & 22 & 50 & 22 \\
\hline \multirow[t]{4}{*}{ Adhesion molecules } & ICAM-1 & 20 & 0 & 0 & 46 & 0 & 33 & 43 & 0 & 33 \\
\hline & ICAM-3 & 10 & 13 & 8 & 10 & 14 & 0 & 29 & 25 & 33 \\
\hline & VCAM-1 & 19 & 13 & 0 & 17 & 0 & 33 & 20 & 13 & 33 \\
\hline & E-SEL & 15 & 0 & 0 & 26 & 0 & 17 & 32 & 50 & 11 \\
\hline \multirow[t]{2}{*}{ Matrix metalloproteinases } & MMP-1 & 17 & 0 & 8 & 20 & 0 & 33 & 19 & 25 & 11 \\
\hline & MMP-9 & 9 & 13 & 8 & 8 & 14 & 17 & 28 & 13 & 44 \\
\hline
\end{tabular}

These are column percents. This table is restricted to infants who delivered for maternal or fetal indications.

Why Did Only a Few Proteins Have Significant Associations in the Multivariable Models?

In parsimonious multivariable models, only those risk factors are added (to the model) that provide unique supplemental risk information. We found that elevated concentrations of only one inflammation-associated protein conveyed information about obesity and only one conveyed risk information about overweight. This was expected in light of the highly intercorrelated relationships among inflammation-related proteins in this cohort (28).

\section{Epigenetic Phenomena/Fetal Programming}

Evidence of presumed fetal programming in the ELGAN study comes from the observation that severely growthrestricted newborns did not have a systemic inflammatory signal on the first postnatal day, but 2 weeks later had a stronger inflammatory response than newborns who were not growth restricted (22). Months later, severely growthrestricted newborns were at increased risk of bronchopulmonary dysplasia (26). Two years later, they were more likely than their peers to have a low score on a cognition assessment (23).

Although our day-1 blood specimens are not umbilical cord specimens, the inflammation evident in these samples does reflect maternal and/or in utero influences $(25,29,30)$. Such early inflammation associated with inflammatory placenta and pregnancy characteristics is markedly diminished by day 7 and essentially no longer evident by day 14 . Consequently, the blood sampled on days 7 and 14, which provide evidence of systemic inflammation, is unlikely to reflect information about predelivery inflammatory stimuli.

In light of these observations, we raise the possibility that some of the early associations with systemic inflammation in our extremely preterm sample might be the evidence of fetal 
Table 6. Odds ratios ( $95 \%$ confidence interval) of having a BMI category of overweight or obese with healthy weight as the reference group at the age of 2 years

\begin{tabular}{llll}
\hline & & \multicolumn{2}{c}{ BMI centile at 24 months } \\
\cline { 3 - 4 } & & $\begin{array}{l}85-94 \\
\text { (Overweight) }\end{array}$ & $\geqslant 95$ (Obese) \\
\hline Pre-pregnancy BMI & $\geqslant 30$ & $1.1(0.5,2.2)$ & $\mathbf{2 . 7}(\mathbf{1 . 1}, \mathbf{6 . 7})$ \\
Sex & Male & $1.7(0.9,3.3)$ & $\mathbf{0 . 4}(\mathbf{0 . 2}, \mathbf{0 . 9 9})$ \\
Multifetal & Yes & $0.8(0.4,1.5)$ & $\mathbf{0 . 2}(\mathbf{0 . 1}, \mathbf{0 . 7 )}$ \\
pregnancy & & $0.8(0.4,1.6)$ & $\mathbf{0 . 2}(\mathbf{0 . 1}, \mathbf{0 . 8})$ \\
Birth weight & $\leq 750 \mathrm{~g}$ & $0.8(0.4,1.6)$ & $\mathbf{2 . 9}(\mathbf{1 . 2}, \mathbf{6 . 8})$ \\
Day 1 proteins & IL-6 & - & - \\
Day 7 proteins & None & $\mathbf{2 . 3}(\mathbf{1 . 2}, \mathbf{4 . 3})$ & $1.6(0.6,4.0)$ \\
Day 14 proteins & VCAM-1 & $\mathbf{0 . 2}(\mathbf{0 . 1}, \mathbf{0 . 6})$ & $1.0(0.4,2.7)$ \\
& MMP-1 & Lowest quartile $0.8(0.4,1.8)$ & $0.3(0.1,1.6)$ \\
Growth velocity & Highest quartile $1.5(0.8,3.1)$ & $2.6(1.00,6.5)$ \\
\hline
\end{tabular}

These time-oriented models are limited to infants delivered for spontaneous indications $(n=563)$. Bold numbers are significantly $>1.0$. Italicized bold numbers are significantly $<1.0$.

programming. If so, the inflammation that we see associated with childhood obesity could be an early expression of the developmental programming that leads to adiposity in later childhood (31).

The intestinal organisms now identified as "gut microbiota" influence the risk of obesity via multiple mechanisms, including energy balance, glucose metabolism, and lowgrade inflammation (32). These observations have led some to view obesity and inflammation as having a common etiology. Indeed, it is likely that a positive feedback loop exists between local inflammation in adipose tissue (e.g., the synthesis of adiponectin, leptin, and resistin) and immune responses elsewhere in the body (e.g., the synthesis of proinflammatory cytokines and related proteins) (8).

\section{Alternate Explanations}

Behavioral explanations may also play a role in the later development of childhood obesity among these infants. Because intermittent and/or sustained inflammation shortly after birth is associated with a variety of disorders in ELGANs, it is possible that the inflammation we associate with later overweight and obesity is really an indicator of the increased risk of disorders that will prompt the parent to perceive her child as more vulnerable than other children. Because parents who perceive their children as vulnerable treat them differently than parents who do not perceive their children as so vulnerable (33), feeding behaviors that distinguish children perceived as vulnerable might differ from those not perceived as so vulnerable (34). Parents and other caregivers who perceive preterm newborns as vulnerable might respond by overfeeding in order to encourage catch-up growth, though this is not known.

\section{Limitations}

We are unable to distinguish between causation and association as explanations for what we found. In addition, the sickest infants were more likely to receive more significant treatment protocols than others who were not quite so sick, making our study prone to confounding by indication, which some feel can never be completely eliminated (35). Compensatory parenting and overfeeding can be viewed as just another form of confounding by indication. With only 34 children delivered for spontaneous indications who developed obesity and 700 children who had not developed obesity at the age of 24 months corrected, our study has a power of 0.83 to detect a doubling of the risk of obesity associated with protein concentrations in the top quartile. Our short-duration measure of growth velocity is limited to the end of the first postnatal month when weights were last obtained routinely.

The interrelatedness of early and late systemic inflammation (36) limits our ability to tease apart the contributions of each to the occurrence of each dysfunction. We are also limited by the relatively small number of proteins measured. Inflammation is a broad and complex phenomenon (37), and we have assessed a very small part of it. In addition, the proteins that we measured might not be in the causal and/or repair chains, but merely surrogates for other proteins in their broad group (38). We relied on blood specimens obtained for clinical indications. As their cardiopulmonary function and blood gas exchange stabilized, infants were less likely than their sicker peers to have blood drawn on day 14 . Consequently, selection bias probably occurred to some extent.

Among the strengths of our study are the selection of infants based on gestational age, not birth weight (39), prospective collection of all data, modest attrition, and finally, protein data of high quality (21), and high content validity $(25,29)$.

\section{CONCLUSION}

In conclusion, obesity at the age of 2 years among children who were born extremely preterm is predicted by perinatal systemic inflammation. This might be a manifestation of fetal programming in the development of obesity and may be critical to our understanding of obesity in all children. Future research should examine if our findings can be replicated among children born very preterm, as well as assessing whether similar fetal programming is evident in children born at term. Preventing and managing obesity in children will require an improved understanding of the multitude of factors involved in the complex development of obesity.

\section{SUPPLEMENTARY MATERIAL}

Supplementary material is linked to the online version of the paper at http://www.nature.com/pr

\section{ACKNOWLEDGMENTS}

Participating institutions and ELGAN Study collaborators who made this report possible: Children's Hospital, Boston, MA: Kathleen Lee, Anne 
McGovern, Jill Gambardella, Susan Ursprung, Ruth Blomquist Kristen Ecklund, Haim Bassan, Samantha Butler, Adré Duplessis, Cecil Hahn, Catherine Limperopoulos, Omar Khwaja, and Janet S. Soul. Baystate Medical Center, Springfield, MA: Bhavesh Shah, Karen Christianson, Frederick Hampf, Herbert Gilmore, and Susan McQuiston. Beth Israel Deaconess Medical Center, Boston, MA: Camilia R. Martin, Colleen Hallisey, Caitlin Hurley, Miren Creixell, and Jane Share. Brigham and Women's Hospital, Boston, MA: Linda J. Van Marter, Sara Durfee. Massachusetts General Hospital, Boston, MA: Robert M. Insoft, Jennifer G. Wilson, Maureen Pimental, Sjirk J. Westra, and Kalpathy Krishnamoorthy. Floating Hospital for Children at Tufts Medical Center, Boston, MA: Cynthia Cole, John M. Fiascone, Janet Madden, Ellen Nylen, Anne Furey Roy McCauley, Paige T. Church, Cecelia Keller, and Karen J. Miller. U Mass Memorial Health Care, Worcester, MA: Francis Bednarek (deceased), Mary Naples, Beth Powers, Jacqueline Wellman, Robin Adair, Richard Bream, Alice Miller, Albert Scheiner, and Christy Stine. Yale University School of Medicine, New Haven, CT: Richard Ehrenkranz, Joanne Williams, Elaine Romano, Cindy Miller, Nancy Close, Elaine Romano, and Joanne Williams. Wake Forest Baptist Medical Center and Forsyth Medical Center, Winston-Salem, NC: T. Michael O'Shea, Debbie Gordon, Teresa Harold, Barbara Specter, Deborah Allred, Robert Dillard, Don Goldstein, Deborah Hiatt (deceased), Gail Hounshell, Ellen Waldrep, Lisa Washburn, and Cherrie D. Welch. University Health Systems of Eastern Carolina, Greenville, NC: Stephen C. Engelke, Sherry Moseley, Linda Pare, Donna Smart, Joan Wilson, Ira Adler, Sharon Buckwald, Rebecca Helms, Kathyrn Kerkering, Scott S. MacGilvray, and Peter Resnik. North Carolina Children's Hospital, Chapel Hill, NC: Carl Bose, Gennie Bose, Lynn A. Fordham, Lisa Bostic, Diane Marshall, Kristi Milowic, and Janice Wereszczak. Helen DeVos Children's Hospital, Grand Rapids, Ml: Mariel Poortenga, Dinah Sutton, Bradford W. Betz, Steven L. Bezinque, Joseph Junewick, Wendy Burdo-Hartman, Lynn Fagerman, Kim Lohr, Steve Pastyrnak, and Dinah Sutton. Sparrow Hospital, Lansing, MI: Carolyn Solomon, Ellen Cavenagh, Victoria J. Caine, Nicholas Olomu, and Joan Price. Michigan State University, East Lansing, Ml: Nigel Paneth, Padmani Karna, and Madeleine Lenski. University of Chicago Medical Center, Chicago, IL: Michael D. Schreiber, Grace Yoon, Kate Feinstein, Leslie Caldarelli, Sunila E. O'Connor, Michael Msall, and Susan Plesha-Troyke. William Beaumont Hospital, Royal Oak, MI: Daniel Batton, Beth Kring, Karen Brooklier, Beth Kring, Melisa J. Oca, and Katherine M. Solomon.

\section{STATEMENT OF FINANCIAL SUPPORT}

This study was supported by The National Institute of Neurological Disorders and Stroke (5U01NS040069-05; 2R01NS040069-06A2), the National Institute of Child Health and Human Development (5P30HD018655-28), and the Office of the Director, National Institutes of Health (1UG3OD023348-01).

Disclosure: The authors declare no conflict of interest.

\section{REFERENCES}

1. Skinner AC, Perrin EM, Skelton JA. Prevalence of obesity and severe obesity in US children, 1999-2014. Obesity 2016;24:1116-23.

2. Skinner AC, Perrin EM, Moss LA, Skelton JA. Cardiometabolic risks and severity of obesity in children and young adults. N Engl J Med 2015;373: 1307-17.

3. Papachatzi E, Dimitriou G, Dimitropoulos K, Vantarakis A. Pre-pregnancy obesity: maternal, neonatal and childhood outcomes. J Neonatal Perinatal Med 2013;6:203-16.

4. Deierlein AL, Siega-Riz AM, Adair LS, Herring AH. Effects of prepregnancy body mass index and gestational weight gain on infant anthropometric outcomes. J Pediatr 2011;158:221-6.

5. Gillman MW, Rifas-Shiman S, Berkey CS, Field AE, Colditz GA. Maternal gestational diabetes, birth weight, and adolescent obesity. Pediatrics 2003;111:e221-6.

6. Parsons TJ, Power C, Manor O. Fetal and early life growth and body mass index from birth to early adulthood in 1958 British cohort: longitudinal study. BMJ 2001;323:1331-5.
7. Stettler N, Stallings VA, Troxel AB. Weight gain in the first week of life and overweight in adulthood: a cohort study of European American subjects fed infant formula. Circulation 2005;111:1897-903.

8. de Heredia FP, Gómez-Martínez S, Marcos A. Obesity, inflammation and the immune system. Proc Nutr Soc 2012;71:332-8.

9. Skinner AC, Steiner MJ, Henderson FW, Perrin EM. Multiple markers of inflammation and weight status: cross-sectional analyses throughout childhood. Pediatrics 2010;125:e801-9.

10. Singer K, Eng DS, Lumeng CN, Gebremariam A, Lee JM. The relationship between body fat mass percentiles and inflammation in children. Obesity 2014;22:1332-6.

11. Lourenço BH, Cardoso MA, Team AS. C-reactive protein concentration predicts change in body mass index during childhood. PLoS ONE 2014;9: e90357.

12. Heerwagen MJ, Miller MR, Barbour LA, Friedman JE. Maternal obesity and fetal metabolic programming: a fertile epigenetic soil. Am J Physiol Regul Integr Comp Physiol 2010;299:R711-22.

13. Hack M, Taylor HG, Drotar D, et al. Chronic conditions, functional limitations, and special health care needs of school-aged children born with extremely low-birth-weight in the 1990s. JAMA 2005;294:318-25.

14. O'Shea TM, Allred EN, Dammann O, et al. The ELGAN study of the brain and related disorders in extremely low gestational age newborns. Early Hum Dev 2009;85:719-25.

15. McElrath TF, Hecht JL, Dammann O, et al. Pregnancy disorders that lead to delivery before the 28th week of gestation: an epidemiologic approach to classification. Am J Epidemiol 2008;168:980-9.

16. National Institute of Health. Classification of Overweight and Obesity by BMI, Waist Circumference, and Associated Disease Risks, 2013. (http://www. nhlbi.nih.gov/health/public/heart/obesity/lose_wt/bmi_dis.htm.) Accessed 23 April 2013.

17. Hecht JL, Allred EN, Kliman HJ, et al. Histological characteristics of singleton placentas delivered before the 28th week of gestation. Pathology 2008;40:372-6.

18. Yudkin PL, Aboualfa M, Eyre JA, Redman CWG, Wilkinson AR. New birth-weight and head circumference centiles for gestational ages 24 to 42 weeks. Early Hum Dev 1987;15:45-52.

19. Kliegman RM, Walsh MC. Neonatal necrotizing enterocolitis: pathogenesis, classification, and spectrum of illness. Curr Probl Pediatr 1987;17:213-88.

20. Kuczmarski RJ, Ogden CL, Grummer-Strawn LM, et al. CDC growth charts: United States. Adv Data 2000;314: 1-27.

21. Fichorova RN, Richardson-Harman N, Alfano M, et al. Biological and technical variables affecting immunoassay recovery of cytokines from human serum and simulated vaginal fluid: a multicenter study. Anal Chem 2008;80:4741-51.

22. McElrath T, Allred E, Van Marter L, Fichorova R, Leviton A. Perinatal systemic inflammatory responses of growth-restricted preterm newborns. Acta Paediatr 2013;102:e439-42.

23. Streimish IG, Ehrenkranz RA, Allred EN, et al. Birth weight-and fetal weight-growth restriction: Impact on neurodevelopment. Early Hum Dev 2012;88:765-71.

24. Laptook AR, O'Shea TM, Shankaran S, Bhaskar B. Adverse neurodevelopmental outcomes among extremely low birth weight infants with a normal head ultrasound: prevalence and antecedents. Pediatrics 2005;115: 673-80.

25. Hecht JL, Fichorova RN, Tang VF, Allred EN, McElrath TF, Leviton A. Relationship between neonatal blood protein concentrations and placenta histologic characteristics in extremely low GA newborns. Pediatr Res 2011;69:68-73.

26. Bose C, Van Marter LJ, Laughon M, et al. Fetal growth restriction and chronic lung disease among infants born before the 28th week of gestation. Pediatrics 2009;124:e450-8.

27. Bose CL, Laughon MM, Allred EN, et al. Systemic inflammation associated with mechanical ventilation among extremely preterm infants. Cytokine 2012.

28. Leviton A, Allred EN, Yamamoto H, Fichorova RN. Relationships among the concentrations of 25 inflammation-associated proteins during the first 


\section{Neonatal inflammation and obesity at age 2 Articles}

postnatal weeks in the blood of infants born before the 28th week of gestation. Cytokine 2012;57:182-90.

29. McElrath TF, Fichorova RN, Allred EN, et al. Blood protein profiles of infants born before 28 weeks differ by pregnancy complication. Am J Obstet Gynecol 2011;204:418. e1-e12.

30. van der Burg JW, Allred EN, McElrath TF, et al. Is maternal obesity associated with sustained inflammation in extremely low gestational age newborns? Early Hum Dev 2013;89:949-55.

31. Ingvorsen C, Brix S, Ozanne SE, Hellgren LI. The effect of maternal inflammation on foetal programming of metabolic disease. Acta Physiol 2015;214:440-9.

32. Cani PD, Osto M, Geurts L, Everard A. Involvement of gut microbiota in the development of low-grade inflammation and type 2 diabetes associated with obesity. Gut Microbes 2012;3:279-88.

33. Miles MS, Holditch-Davis D. Compensatory parenting: how mothers describe parenting their 3-year-old, prematurely born children. J Pediatr Nurs 1995;10:243-53.
34. Pridham K, Melby JN, Brown R, Clark R. The contribution of infant, maternal, and family conditions to maternal feeding competencies. Parent Sci Pract 2010;10:18-42.

35. Bosco JL, Silliman RA, Thwin SS, et al. A most stubborn bias: no adjustment method fully resolves confounding by indication in observational studies. J Clin Epidemiol 2010;63:64-74.

36. Dammann O, Allred EN, Fichorova RN, et al. Duration of systemic inflammation in the first postnatal month among infants born before the 28th week of gestation. Inflammation 2016;39:672-7.

37. Zak DE, Aderem A.. Systems biology of innate immunity. Immunol Rev 2009;227:264-82.

38. Becher B, Spath S, Goverman J. Cytokine networks in neuroinflammation. Nat Rev Immunol 2017;17:49-59.

39. Arnold C, Kramer M, Hobbs C, McLean F, Usher R. Very low birth weight: a problematic cohort for epidemiologic studies of very small or immature neonates. Am J Epidemiol 1991;134:604-13. 